\title{
Chagas Disease: Proposal of Health Education for Community Health Workers in the City of Petrolina, Pernambuco, Brazil
}

\author{
Alexsandro Paulo Costa Galdino Junior'1, Cícera Aurea Fontes Vilela², \\ Ícaro Sampaio Inácio', Jamille Conduru Mendes Segatto ${ }^{3}$, \\ Mykaelly Pereira Clemente ${ }^{2}$, Ricardo Santana de Lima ${ }^{1}$ \\ ${ }^{1}$ Medical School, Federal University of Vale do São Francisco, Petrolina, Brazil \\ ${ }^{2}$ Nurse Family Health Strategy of the City Petrolina, Petrolina, Brazil \\ ${ }^{3}$ Biological Sciences, Federal University of Vale do São Francisco, Petrolina, Brazil \\ Email: alexgaldinojr@hotmail.com, icaro.spi@hotmail.com, jamilleconduru@hotmail.com, \\ mykaellypc@hotmail.com, aureavilela@hotmail.com,ricardo.lima@univasf.edu.br
}

Received 11 May 2015; accepted 28 December 2015; published 31 December 2015

Copyright (C) 2015 by authors and Scientific Research Publishing Inc.

This work is licensed under the Creative Commons Attribution International License (CC BY). http://creativecommons.org/licenses/by/4.0/

(c) (i) Open Access

\section{Abstract}

The Education for Health at PET Work Program (PET-Health) is focused on education as a presupposition. Actions are directed towards to the integration of service-learning and community. Interdisciplinary principle is directed from fusion of work of graduate students, academics and professionals of health services for the benefit of strengthening primary care and health surveillance. This work aimed to carry out educational activities with Community Health Agents (ACS) of the health facilities of PET-health, with the theme of Chagas disease. This descriptive cross-sectional study was carried out from January to May 2013, and the sample consisted of 25 active ACS in six Basic Health Units in the city of Petrolina, Brazil. In spite of actuation of ACS in primary care for over 10 years, a limited knowledge has been developed about this pathology. The health education workshops developed by the PET group clarified the ACS on Chagas disease allowing them to have an expansion of knowledge about the vector, habitat Barber, transmission, clinical manifestations... After the workshop, it was found that the ACS expanded their knowledge about the disease cycle, expanding the possibilities for action in the prevention of this pathology in their respective coverage areas. This work shows an important form of integration between education, service and community that can govern the new direction of health education.

\section{Keywords}

Chagas Disease, American Trypanosomiasis, Health Education, Primary Health Care, Public Health 


\section{Introduction}

After health reform in the early 80s, health in Brazil has advanced, for example, with the establishment of the universal right to health guaranteed in the 1988 Constitution and the organic Law of health [1] establishing the Unified Health System (SUS) as a national policy ensuring that health is a right and duty of the state.

In 1994, as a way to strength the current public health policy, the Family Health Program (PSF), now called by the Family Health Strategy (FHS) arises, having its policy instituted in 2006 with the establishment of the National Primary Care, presenting itself as an input device in the SUS in which it recommends, especially the health promotion and diseases prevention that come to allow this universal access to health care for the population, among other acquired rights [2].

However, despite the legal and political developments, there was a need to prepare professionals to act with these new forms of health care. In 2008, through ministerial decree MS/MEC No. 1802, to August 26, 2008, the Education Program At Work for Health-PET-health was established, inspired by the Tutorial Education Program [3] [4]. The PET-health emerges as a strategy of reorientation training for SUS, particularly for primary care relying on guiding thematic lines that allow the academic community and in the service of teaching approaches, enabling a process of lifelong learning.

Chagas disease is the first theme in these lines. It is known that this disease was first described in 1909 in Minas Gerais, by Carlos Chagas who launched the Brazilian medicine in the global scientific community, identifying Chagas disease, since the parasite (Trypanosoma cruzi), until its cycle life, definitive hosts and intermediate mode of transmission and disease progression [5] [6]. Since then, this disease is known worldwide, nevertheless the disease is considered neglected, since it affects the countries in the tropics, which provides a fast pace in research as compared with other chronic diseases such as hypertension, diabetes and cancer [7]. The American Trypanosomiasis or Chagas disease (CD) is a major neglected tropical disease, caused by a flagellate parasite, Trypanosoma cruzi. This disease is endemic in Latin America, which has a prevalence of approximately $1.4 \%$ and kills 14,000 people each year, which is higher than the number of deaths caused by other parasitic diseases in the region, including malaria [7] [8]. The estimated number of people infected with T. cruzi is round 8 to 14 million, with more than 100 million people at risk of acquiring Chagas [9]. In the past, DC was confined to endemic areas; however, with the intense migration of Latin Americans, the problem became global [9].

The consequences resulting from Chagas disease is a burden to public health. According to data from the Financier of Studies and Projects (FINEP), published in the journal Innovation in Tariff No. 6 of December 27, 2012, Brazil invests about seventy-five million dollars per year in research on neglected diseases. In the same magazine, the author of article Flávio Pontes points out that being a neglected disease, Chagas disease has no official numbers. However, it estimates that in Brazil, currently it concentrates $23 \%$ of the infected, being the country with the most endemic cases. It also shows that more than fourteen thousand people die each year per DC, surpassing deaths from malaria [10].

Given the above, the PET-Health has been using permanent education in health problems such as attenuator mechanism, focusing on educational workshops as a means of combating this disease strategy.

It is understood that such programs, aimed at excellence in providing health services to the population, need to be encouraged and recommended. Therefore we developed a work that sought to relate the experience of Health Education in teams of the Family Health Strategy, with the aim of disclosing positive outcome results of PET-health professional reorientation process.

This work aimed to carry out educational activities on the theme of Chagas disease with the Community Health Agents (ACS) in health facilities of the city of Petrolina-Pernambuco presenting them with the clinical and epidemiological knowledge of the disease, bringing them closer to the university and providing the group of popular promotion and health education activities in the context of family health strategy.

\section{Methodology}

The "Educating about Chagas" project was conducted from January 2013 to May 2013 by three students of the group PET-Health, under the supervision of a health professional in the municipality (Preceptor). All members of the research Epidemiology and Health Education for Chagas disease in the city of Petrolina, Pernambuco, Brazil. The activities were developed in 6 Basic Health Units-UBS the municipality. The target public was 25 Community Health Workers-ACS, working in the area of coverage of these UBS. There were five meetings between the group and the ACS. The project was carried out in six steps, as described in this order. 


\subsection{Training Group}

Members of the group were submitted to a training process where everyone participated in lectures and discussed clinical cases covered matters relating to the history, epidemiology, etiology, vector, pathophysiology, clinical presentation, treatment and prevention of Chagas Disease. And a literature review was conducted this way the group became able to promote health education with the ACS.

\subsection{Search-First Phase}

A descriptive cross-sectional study with a sample of 25 ACS of six basic health units in the city of Petrolina, Pernambuco, Brazil was performed. For data collection an anonymous questionnaire (pre-test), with open and multiple-choice questions was used. The questions addressed professional aspects, beyond the knowledge of ACS about Chagas disease. The application of the instrument was performed in the first meeting between the group and the ACS. At this point, the project objectives and the methodology were exposed.

\subsection{Expertise in the Education of Community Health-ACS}

The process of health education occurred through workshops. Images, texts and instructional videos, informative booklet were used for the workshops, and lectures prepared by the group based on the literature review previously addressing aspects of Chagas disease.

The intervention phase consisted of three workshops, which started from the second meeting with the agents. In the first of these were addressed the history and epidemiology of Chagas disease. The second time the team has discussed aspects related to the parasite and the vector of the disease. The third workshop was focused on the understanding of some pathophysiological and clinical aspects of parasitosis, besides clarifying issues of prevention of disease.

During the workshops, the actors were encouraged to expose doubts and assess the risk to which the community in which they operate is exposed. Also, highlighted the importance of the information acquired during the meetings were provided to the population. All agents were given educational material containing the main topics discussed in the workshops.

\subsection{Search-Second Phase}

During the fifth and final meeting with the new ACS questionnaire (post-test) was applied. As the pre-test, the instrument consisted of open and multiple choice questions, addressing only aspects related to Chagas disease.

\subsection{Evaluation of Activities}

With the end of the project, the team requested that health workers evaluate the activities developed and do suggestions. All ACS received a participation certificate, which certified them as "Sentinels Carlos Chagas" in honor of the discoverer of the disease and as a way to reinforce the importance of attention to this disease in their area of expertise.

\subsection{Data Analysis}

For data analysis tool Google Drive was used for the compilation of the questionnaire responses and analyzes and graphs posted in Office Excel 2013. A comparison between the responses of the first and second questionnaire permitted an objective evaluation of education activities. As inclusion criteria, only data from the ACS that participated in the workshops and who answered the pre-test and post-test were used.

\subsection{Ethical Aspects}

This work followed the guidelines of Resolution No. 466 of December 12, 2012, the National Board of Health/ Ministry of Health (CNS/MS). Therefore all participants signed a consent form, in two copies, one remaining with the researcher and the other with the subject of the study. The project was approved by the Ethics Committee and Ethics Studies and Research-(CEDEP) and is recorded under No. 0003/180213 CEDEP/UNIVASF. 


\section{Results and Discussion}

\subsection{Characterization of the Research Subjects}

Participated in this study twenty-five Community Health Agents (ACS) aged between 23 and 54 years, among whom $44 \%$ had more than 10 years experience in primary care.

The sample was characterized by a predominance of females (72\%) and educational level secondary education (60\%). Relevant was the fact that $4 \%$ of respondents have postgraduate, $16 \%$ university graduates and $20 \%$ higher education course.

Of the 25 Community health workers only five over the professional time spent by workshops or training on Chagas disease, and the last that has gone through this training event did about three years.

We know that continuing health education (EPS) provides different forms of learning, including exchanges of knowledge and reflection of daily activities, making use of strategies providing critical look at the practices of service, enabling changes in relationships, behaviors and attitudes of all staff [11] [12].

Therefore, health education should be considered as an important component of the monitoring programs, individualizing the social and cultural context of the community. Among the issues to be addressed, priority should be given a demonstration of the triatomines as transmitters and active community participation. Interestingly also, the use of appropriate methodologies to facilitate the transformation of knowledge into attitudes and preventive practices by the community which effectively passes to contribute to the control of the disease [11] [13]. Of ACS who participated in this study 52\% never followed any cases of patients with Chagas (acute or chronic) disease in their area of expertise.

From the data, it is understood, therefore, the fact that $100 \%$ of the sample report that does not feel prepared to act on the prevention and control of Chagas disease. Lack of information, knowledge and capabilities were mentioned as the main causes of this insecurity.

\subsection{Chagas Disease: Transmission and Symptoms}

Carlos Chagas, in 1909, discovered the route of vectorial transmission of Chagas disease. Currently this is not the most important form of transmission due to the improvement of housing and combating insect vector campaign. Consequently, other modes of transmission have become more relevant as transplacental, transfusion and oral, and other less known, such as handling of infected animals, accidents in the laboratory, breastfeeding and organ transplantation [14].

After the workshops it was found that the ACS started to identify other means of transmission, expanding their knowledge about this stage of the disease cycle and the performance possibilities for its prevention in their respective coverage areas. This result is quite clear from the comparative analysis of data from the pretest (Table 1) and posttest (Table 2).

Table 1. Recognition of the transmission means of Chagas disease by ACS. Data from the PRE-TEST.

\begin{tabular}{cccc}
\hline $\begin{array}{c}\text { Blood transfusion, Vector bite, } \\
\text { Ingesting contaminated food }\end{array}$ & $\begin{array}{c}\text { Blood transfusion, } \\
\text { Vector bite }\end{array}$ & $\begin{array}{c}\text { Vector bite, Ingesting } \\
\text { contaminated }\end{array}$ & 7 \\
\hline 6 & 3 & 9 \\
\hline
\end{tabular}

Table 2. Identification of the mode of transmission of Chagas disease by ACS. Data from the POS-TEST.

\begin{tabular}{|c|c|c|c|c|c|c|c|}
\hline $\begin{array}{c}\text { Blood } \\
\text { transfusion. } \\
\text { Vector bite, } \\
\text { Ingesting } \\
\text { contaminated } \\
\text { food, Vertical } \\
\text { transmission }\end{array}$ & $\begin{array}{c}\text { Blood } \\
\text { transfusion, } \\
\text { Vector bite, } \\
\text { Ingesting } \\
\text { contaminated } \\
\text { food }\end{array}$ & $\begin{array}{c}\text { Blood } \\
\text { transfusion, } \\
\text { Vector bite }\end{array}$ & $\begin{array}{c}\text { Blood } \\
\text { transfusion }\end{array}$ & $\begin{array}{l}\text { Vector bite, } \\
\text { Ingesting } \\
\text { contaminated } \\
\text { food }\end{array}$ & $\begin{array}{c}\text { Ingesting } \\
\text { contaminated } \\
\text { food }\end{array}$ & $\begin{array}{c}\text { Sexual } \\
\text { contact, Blood } \\
\text { transfusion, } \\
\text { Vector bite }\end{array}$ & $\begin{array}{c}\text { Sexual } \\
\text { contact, Blood } \\
\text { transfusion, } \\
\text { Ingesting } \\
\text { contaminated } \\
\text { food }\end{array}$ \\
\hline 4 & 9 & 5 & 1 & 3 & 1 & 1 & 1 \\
\hline
\end{tabular}


We realize that, before the intervention, most believed to be the bite of the vector only way transmission of Chagas disease (Table 1).

It was observed that after the intervention the ACS can more easily identify other forms of transmission for Chagas disease vector transmission beyond (Table 2).

We also observed that $32 \%$ of ACS, early intervention, could not identify the insect responsible for the transmission of Chagas disease, which hampers early detection of these insects and thus impairs the efficiency of surveillance.

Studies show that, often, knowledge about vectors in endemic areas is limited and it undermines the development of control programs, since for that community participation and achieve better results this way is avoid underreporting, it is necessary that residents will acknowledge the triatomine and its role in the transmission of $T$. cruzi [13].

Studies in rural counties in the state of Paraná found a lack of interest from residents in relation to know the triatomines. Still in Paraná, many health professionals evaluated demonstrated immense ignorance about relevant aspects of Chagas disease, as transmission and prevention [15].

Due to limited clinical manifestation in acute case, an important component of surveillance is the recognition of the vector that is the most sensitive method of entomological research for triatomines, in situations where the densities of the resident populations are minimal [11] [12].

A positive factor was that after the workshops ACS reported no difficulty in recognizing the vector and show it to the community as a possible transmitter of the disease in question.

They also began to identify local habitat of the insect, which combined with the knowledge about the modes of transmission, lets act at other points in the life cycle of the disease and can fight more forcefully its vector.

When asked about the organs affected by Chagas disease, in principle, the vast majority (76\%) reported only the heart as the organ affected. Another $20 \%$ recognized that beyond the heart, the gut was also the target of this pathology. Data from the post-test showed that $88 \%$ of ACS now know how to identify all the organs affected by Chagas disease.

It is known that cardiac involvement presents variant gravity, with various manifestations, ranging from examinations subtly altered to heart failure or sudden death. The digestive tract is also affected by the chronic form of Chagas' disease, especially the esophagus, the intestine and the colon. Still occurs impaired autonomic nervous system, through injury, denervation and functional disorders [11] [12].

Furthermore, we observed the motivation of these professionals improve their knowledge on this topic during the intervention, as some of them reported having attended additional courses on the subject even during the workshops.

25 of the ACS sample, 20 had never received any guidance bend Chagas disease and of these, $15 \%$ sought more still during the procedure qualification demonstrating substantial interest about the topic.

Upon completion of the workshops it was found that the ACS were already applying the knowledge acquired in the community through lectures, orientations, wheels conversations and monitoring of suspected cases (Table 3).

This event highlights the social relevance of this research.

\section{Conclusions}

Recognizing the importance of the Labor Education Program for Health, PET-Health in the integration of the teaching-service-community believes that continuing education in health is an educational activity with a guideline directed to the transformation of the labor process; We consider this important work from a social point of view since there was a theoretical and practical improvement by the ACS regarding Chagas disease.

We realize that while some ACS had a high level of education, as higher education and even graduate, prior knowledge about Chagas disease was limited.

Table 3. Statements made by ACS focusing in patients with Chagas disease, after the workshops. Data from the POSTTEST.

\begin{tabular}{cccc}
\hline No yet done & $\begin{array}{c}\text { Done: Followed a } \\
\text { suspected case }\end{array}$ & Done: Orientation & Done: Lecture \\
\hline 17 & 1 & 1 & 3 \\
\hline
\end{tabular}


The workshops helped clarify the ACS on Chagas disease allowing them to have an expansion of knowledge about the vector, habitat Barber, transmission, clinical manifestations, etc.

Students also had limited knowledge about this disease. The preparation of workshops this knowledge led to the development and leveling the same, since the students were courses and different periods.

It was found that, indeed, the PET-Health approach allows the student to the service, even before the mandatory internship or clinical disciplines, enabling the academic to rethink the curative model of health courses because they think the PET-health as a developer of comprehensive care, and entering the student in primary care, through programs that allow such reflections about the payment of health care.

The transformations in the labor process were notorious in the area of operation of the ACS. Certainly the community assisted by these professionals will be better able to combat Chagas disease after receiving clear guidance from them.

We recognize that health education with practical application in the community is a strategy to strengthen the Primary that can contribute to the health surveillance of neglected diseases and other illnesses. This paper reports this theory through statistical description of the intervention of PET-health redesign of teaching in educational and health services.

\section{References}

[1] Thürler, L. (2012) SHS—Single Health System. (SUS—Sistema único de saúde). 3rd Edition, Campus, São Paulo.

[2] Ministry of Health (Brazil) (2011) Assistance Secretary of Health. Health Coordination of the Community. Family Health: A Strategy for Reorienting the Care Model. Ministry of Health, Brasilia.

[3] Ministry of Education (Brazil) (2008) Ministerial Decree No. 1802 of 26 August 2008. Establishes the Education Program for Working for Health-PET-Health Brasilia.

[4] Brazil (2005) Law No. 11129 of 30 June 2005. It Establishes the National Program for Youth Inclusion. Official Gazette. Brasilia, 1 July 2005; Section 1, 1.

[5] World Health Organization (2013) Chagas Disease (American Trypanosomiasis) [Internet]. http://www.who.int/mediacentre/factsheets/fs340/en/

[6] Dias, J.C.P. (1999) Epidemiology. In: Brener, Z. and Andrade, Z., Eds., Trypanosoma cruzi and Disease Chagas, Guanabara Koogan, Rio de Janeiro, 48-74.

[7] World Health Organization (2011) Working to Overcome the Global Impact of Neglected Tropical Diseases. http://apps.who.int/iris/bitstream/10665/44440/1/9789241564090_eng.pdf

[8] Schmunis, G.A. (1997) American Trypanosomiasis: Their Impact in the Americas and Prospects for Elimination. In: Days, J.C.P. and Coura, J.R., Eds., Clinic and Therapy of Chagas Disease: A Practical Manual for the General Practitioner, Editora Fiocruz, Rio de Janeiro, 11-24.

[9] Ribeiro, I., Sevcsik, A.M., Alves, F., Diap, G., Don, R., Harhay, M.O., et al. (2009) New, Improved Treatments for Chagas Disease: From the R \& D Pipeline to the Patients. PLOS Neglected Tropical Diseases, 3, 484. http://dx.doi.org/10.1371/journal.pntd.0000484

[10] Pontes, F. (2014) Neglected Diseases Still Kill 1 Million a Year Worldwide. Revista Inovação em Pauta, 6, 69-73.

[11] Silva, P.D.F. (2012) Characterization of the Reactivity of Antibodies in Clinical Forms of Chagas Disease by the Use of Peptides Identified by Phage Display Technology for the Discovery of Serological Markers with Diagnostic and Prognostic Value. Master's Dissertation, Federal University of Triangulo Mineiro, Uberaba.

[12] Silva, L.A.A., Bonacina, D.M., Andrade, A. and Oliveira, T.C. (2014) Challenges in Building a Permanent Education Project in Health. Revista de Enfermagem da UFSM, 2, 496-506.

[13] Maeda, M.H. and Gurgel-Gonçalves, R. (2012) Knowledge and Practices of Residents of the Federal District, Brazil, in Relation to Chagas Disease and Their Delivery Systems. Revista de Patologia Tropical, 41.

[14] Rotta, D.S., Siqueira, L. and Pedroso, D. (2013) Congenital Transmission of Chagas Disease: A Review. Arquivos de Ciências da Saúde, 20, 140-146.

[15] Falavigna-Guilherme, A.C., Costa, A.L., Batista, O., Pavanelli, G.C. and Araújo, S.M. (2002) Health Education for Triatomine Control in Surveillance Area of Paraná State, Brazil. Cadernos de Saúde Pública, 18, 1543-1550. http://dx.doi.org/10.1590/S0102-311X2002000600007 